\title{
Application of federal character policy: role and constraint of the civil society in Nigeria
}

\begin{abstract}
The role of civil society in the application of the federal character policy in Nigeria is the focus of this study, with emphasis on the opportunities and constraints that civil societies face in promoting and ensuring the adherence of the policy in the country. Considering the fact that task of policy application would become a mirage if the government isolates the civil society whose conspicuous role in the overall adherence of the policy cannot be overemphasized. And in order to achieve the objectives of this study, secondary source of data was used with content analysis. The study discovers that civil society in Nigeria remains an important and crucial stakeholder in the application of the federal character policy especially in the area of advocacy and policy orientation. However the efforts of the civil society are being hampered by some constraints like lack of strong constitutional recognition and finance challenges amongst other. Hence the study recommends a constitutional role for the civil society and financial support in the overall interest of achieving the policy objectives of the Federal character.
\end{abstract}

Keyword: Civil society; Federal character policy; Policy change; Advocacy and policy agenda 